\title{
A Rationalist Critique of Sally Gadow's Relational Nursing Ethics
}

\author{
Uche S. Odozor, Helen N. Obilor, Olasupo O. Thompson and \\ Ngozi S. Odozor \\ http://dx.doi./org/10.4314/ujah.v22i1.2
}

\section{Abstract}

The ethic of care proposed by Carol Gilligan in late twentieth century instantly elicited a wide range of adaptations and elaborations in numerous disciplines, under the banner of 'relational ethics'. Sally Gadow's 'relational narrative' is one of these adaptations. Like Gilligan, Gadow aims to dismantle ethical rationalism or universalism, wherein the foregoing mainstream nursing practice had purportedly focused on applying existing philosophical theories of ethics to all conceivable clinical situations. For Gadow, every moral engagement, such as that between a nursing professional and a patient, comes with inherent unique features that render impotent any attempt at universalisation. Each clinical encounter is rather defined by the ability of the professional to engage the client in an intimate, caring relationship that enables healing to take place. Against this backdrop, this paper argues that the theory of Relational Narrative, particularly as conceptualised and articulated by Sally Gadow, cannot be carried through without making some rationalist assumptions, because professionalism in nursing practice is by definition, a deeply embedded ingredient of rational reflection. Furthermore, nursing professionals can make progress or impact only by having recourse to the code of ethics; also, direct application of Gadow's theory puts the nurse in a dilemma when it comes to dealing with patients suffering from chronic contagious 
diseases, such as the Ebola or the coronavirus disease (COVID-19). Finally, juxtaposing Gadow's work with the ideas of the earlier scholars she criticises unsparingly, the paper found that traces of universalist, rationalist assumptions abound in her thought precisely because of the wealth of influence she has garnered from philosophers and psychologists; influences going as far back as Descartes and Kant, down to Rawls and Kohlberg. The data used for this study came from library and archival materials, as well as from internet resources.

\section{Keywords: Care, Ethics, Gadow, Relational Narrative, Universalism}

\section{Introduction}

Following Carol Gilligan's revolutionary work on care ethics, many scholars in numerous fields of research, including medicine, sociology, philosophy and psychology, have tended to discredit traditional ethical theories of philosophers and social theorists, by viewing them as too rationalistic or universalistic and, therefore, irrelevant for dealing with concrete human moral encounter and experience. One of the notable problems posed by this relational approach to ethical thinking is that it has created a deep gulf between human rationality or reason and the emotions, thereby suggesting that these human faculties cannot be possibly reconciled in actual human experience and practice. Sally Gadow's relational narrative theory of nursing ethics is, on a judicious reckoning, a fairly good example of the application of this recent approach to field of nursing. According to Gadow, the nursing profession would better attain its goals of caring for, and bringing healing to, 
patients if nurses became emotionally engaged, or related more closely, with their clients than if they simply continued to resort to extant rational ethical principles and universal standards laid down by philosophers, as has hitherto been the practice. Relational narrative, as proposed by the philosopher nurse, Gadow, is basically an attempt to deconstruct traditional ethics, as represented by prominent philosophers, such as Kant, Mill, Moore and Rawls, and psychologists, such as Kohlberg, all of whose ethics Gadow overrules as "rational ethical universalism."

Gadow's relational narrative is, thus, a subset of relational ethics, or ethics of care, which has been a subject of keen interest in recent decades among nursing professionals, as well as clinical therapists and psychologists. This paper is a critical exposition of Sally Gadow's relational narrative theory of nursing ethics. The paper aims to determine the implications of Gadow's work for postmodern philosophical ethics, and to demonstrate that Gadow's proposed new approach cannot proceed without being based on rationalist assumptions. The paper is organised as follows: first, Gadow's relational narrative is discussed and traced to the foregoing scholars, such as Immanuel Kant, Maurice MerleauPonty, Lawrence Kohlberg, John Rawls, and Carol Gilligan, whose works have influenced her ideas. The next section explores subsequent elaborations of Gadow's thought by prominent scholars in the health care profession, such as Vangie Bergum and Joanne D. Hess. The last section is the critique of relational narrative, as developed and proposed by Gadow. In conclusion, the paper submits that Sally Gadow's work is an interesting and important offshoot of ethical discourse, but that it can accomplish the desired goals only by coming to terms with the mainstream rationalist ethical thought that went before it. 


\section{Sally Gadow's Relational (Narrative) Ethics}

In a 1999 article, the philosopher nurse, Sally Gadow, discusses three layers of ethical approach that have been separately adopted in the nursing profession. The first is subjective immersion (ethical immediacy), which in Gadow's reckoning, corresponds to premodern ethics. This is where the nurse unreflectively plunges into a clinical situation, deriving the idea of what is good for the patient by immediately resorting to personal convictions, as informed by religion, custom, family tradition, or ethos of the profession. Gadow (1999, p.60) explains it as follows:

With a cultural, professional, or religious basis for certainty, a nurse intuits the good directly, without recourse to reflection. That immediacy is the phenomenon I call immersion: a nurse is immersed in a tradition that provides an ethical appraisal of the situation, as well as immersed in the situation itself.

The second layer is modern detachment (corresponding to rational, ethical universalism), in which the nurse, like a professional, simply adopts readily established rational ethical principles believed to be universally applicable across all similar, or related cases. An example of these principles is the widely accepted philosophical belief that individuals ought to be accorded equal respect due to "the rational autonomy" allegedly possessed by each person, for which they have to be treated "as ends in themselves" (Gadow, 1999, p.61). But ethical principles, though psychologically persuasive, lose their universality because they engender conflicting interpretations in actual clinic settings, due to the differing perspectives of those involved, and because blind 
application of principles strips persons and their situations of their unique, lived realities and experiences.

The third, known as relational narrative, is "the construction by patient and nurse of an interpretation that is their coauthored narrative describing the good they are seeking" (Gadow, 1996, p.8; cited in Hess, 2003, p.137). Gadow (1999, p.57) describes this situation as "the postmodern turn in nursing ethics," this layer refers to the proposal that nursing professionals begin to engage their clients with a relatively high degree of empathy by trying, as much as possible, to understand and closely accompany their patients as subjects of clinical therapy, rather than as objects of mere clinical curiosity and interest. Professionals must appreciate the pains and troubles of patients, by accompanying the latter in the process of healing and recovery. Instead of standing aloof and detached from the patient in a fashion that is devoid of feelings and emotions, as instantiated by the application of abstract universal ethical principles of philosophers, and as demanded by the extant professional code of ethics, nurses can achieve better results by going beyond the sense of duty in order to develop an empathic relationship with their clients, viewing the latter as co-subjects of clinical therapy.

According to Gadow, both nurse and patient must - as coworkers or co-authors - enter into a mutual relationship that enables them to create a narrative, or a story, embodying the true feelings and experiences of the patient, with the nurse not allowing his or her special training and expertise overshadow what the patient actually feels, or has to contribute to the process. Every clinical encounter comes with inherent peculiarities and uniqueness. It involves the reality, here and now, of a nurse and a patient, both of whom are embodied beings facing a real situation 
that differs in a number of ways from other situations. Each encounter or experience is, therefore, contingent and assumes no absolutely necessary form. Thus, the professional must be able to work with a client to reach "the good" of the situation, as explicitly defined by the peculiarities of each case and the particular circumstance of the client, rather than resort to rote application of abstract universal ethical principles that gloss over the uniqueness and the existential realities of these individuals in a clinical encounter.

Ethics and morality typically come into play in (intersubjective) human relationship; that is, in a situation where people treat each other in a certain way. This implies that relationship is inherent to ethics (Johnson, 1989; Barcalow, 1994; Rachels, 2003). More importantly, it implies that aside the ethical codes of the profession, a nurse is also engaged in a higher level of ethical experience with a patient. The idea of "care respect" is, to all intents and purposes, the common ground where the relational narrative theory resonates with Carol Gilligan's ethics of care. Gadow (1999, p.63) explains this connection in her long-running critique of universal ethical rationalism:

Respect for persons as existential selves involves more than detached regard for abstract autonomy; it entails attentive discernment and valuing of an individual as unique. Dillon (1992[p.120]) describes this discernment as care respect, because its valuing of particularity parallels that of care ethics. The valuing of persons requires perception of each one's uniqueness, and perception involves engagement. In contrast to rational ethics, which 32 
demands detachment in order not to perceive people concretely or respond to them personally, care respect conveys "cherishing, treasuring, profoundness of feeling."

Rationalism, in the 17th century sense, is the epistemological persuasion that reason, prior to sense experience, is the valid means of gaining knowledge of the external world. It stood opposed to empiricism, which held that the senses are the means of knowing the world, rather than the faculty of reason (Hamlyn, 1967). Thus, Gadow's application of the concept of rationalism in ethics is much broader than traditional philosophical rationalism. It includes, for example, Kant, the Utilitarians, Hare, and even Rawls, each of whom argued for some rationally derived theory of the good for humans in society, after due critical refection. Ethical rationalism, as conceptualised by Gadow, therefore, refers to all those ethical theories which tended to establish purported universal principles that are taken as applicable to every moral situation.

\section{Gadow's Influences}

Although it is not explicitly stated, it is evident that the tradition Gadow alludes to in her critique of ethical rationalism is a longestablished one that goes back, at least, to Immanuel Kant (1785/1953, pp.70, 95-96), who projects his moral philosophy as maxims; the first maxim, as a "universal law", and the second, as "respect for persons as ends in themselves," due to the rational nature of humans. Besides, Kant's ethics is known as the "ethics of duty," due to his insistence that sense of duty, rather than consequences or outcomes, is the driving force of human ethical conduct (Stratton-Lake, 2006, p.330). Another instance of this 
rational tradition is Utilitarianism, which bloomed in the nineteenth century with purported "Greatest Happiness Principle" that it proceeded to apply indiscriminately to all humans everywhere and in all circumstances (Barcalow, 1994, p.117; Rachels, 2003, p.92). Early twentieth century ethics saw the unfolding of Personalism, which appreciated and emphasised the physical and genetic uniqueness of each person as mark of human dignity, and maintained that each person is an original and unique expression of human nature (for instance, MacMurray, 1935). Social theorists, such as Owens (1969, p.241), have contended for the "absolute rights [of humans] as persons" which must never be violated in any circumstance. Also, Rawls (1971, p.3-4) is in consonance with Kant and the early social contract theorists (for example, Locke and Rousseau), against the Utilitarians (Bentham, Mill and Sidgwick), that humans are rational beings with rights "that even the welfare of society as a whole cannot override"; rights which "are not subject to political bargaining or to the calculus of social interests."

The underpinnings of this rationalist system influenced scholarly work farther afield. One of the particular areas that psychologists have made valuable contributions to the understanding of morality is in their work on the development of moral consciousness in young human beings. Lawrence Kohlberg (1958, 1984), for example, undertakes a series of research culminating in his extensively discussed six stages of moral development:

Stage 1: stark obedience to rules in order to avoid punishment Stage 2: following reciprocal fairness rules for mutual benefit; 
Stage 3: internalising rules and conventions of the family and peer group;

Stage 4: internalising norms and laws of society;

Stage 5: reasoning about the principles behind social laws; and, finally,

Stage 6: reasoning purely from these principles, regardless of social or cultural norms.

For Kohlberg, just as for Kant and Rawls, the fundamental principles of moral reasoning include fairness, equality and justice; and moral development consisted in the personal, increasingly sophisticated understanding of these principles. However, Kohlberg persuades that ethical approaches centering on character, values or virtues did not promote the development of moral reasoning, because, according to him, a well-developed system of moral education should expose a person through the stages listed above.

Carol Gilligan $(1982,1990)$ objects to Kohlberg's theory. For her, Kohlberg squarely focused on the moral development of young males, and overlooked that of girls. She reckons that gender plays a central role in moral development of men and women, particularly because each gender interprets and conceptualises moral issues somewhat differently. Simply put, men and women differ in their attitudes to moral situations. Kohlberg may be right that moral principles are important in ethical decision-making; but this only applies to the male folk, who typically go by "relying on formal rules and abstract principles to define right and wrong" (Macionis and Plummer, 2005, p.526). Men simply apply pure, abstract logical reasoning to determine which sorts of action and conduct are wrong or right, in order to reach conclusions about 
what is morally good or bad, what is the right thing to do in any circumstance. But women are led by the concrete circumstance in which a particular moral situation puts them. They ask whether blind application of justice, for example, would make a bad situation worse, hurt more people, increase the burden already borne by the moral agents, and so on (Rachels, 2003, p.162f.). Thus, with women, ethics is approached from the perspective of care, responsibility and loyalty towards family, friends, personal relationships, society, and the like. Unlike men, who would stand from a distance and invoke the necessary ethical principles without sparing a thought for the peculiarities and contingencies of each moral encounter, the female gender tends to relate closely with the ethical situation and get dissolved in it, in the process.

\section{Elaborations of Gadow's Thought}

Gadow's work has received some elaboration from contemporary scholars drawn to relational ethics. For example, Hess (2003) argues that Gadow's relational narrative can, at bottom, be construed as a comprehensive moral guide that enables both nurse and patient to successfully navigate the entire process of clinical engagement. To achieve this, relational narrative must be cultivated ontologically and epistemologically; that is, it must be imbibed as "a way of being as well as a way of knowing for patient and nurse and ... grounded in a subjectivity extending beyond socioculturally defined norms and role expectations" (p.147). Exploring the role of narrative in the realm of morality, Hess notes that not only is relationship foundational to the process, narrative lies at the heart of the encounter between the two healthcare stakeholders. She 
proffers the following practical suggestion on how to go about the proposed manner of clinical encounter:

Within a relational narrative, engagement allows the nurse to empathically understand the patient's perspective and to share the ill person's vulnerability by answering the question, 'What is it like?' What is it like to be ill, to gain health, to lose a loved one, to lose our selves to illness, to suffer until a new self and a new story are crafted? The only way to understand others and their experience and world is to engage them as subjects, not as objects of our care (p.146).

The process, once appropriately set on course, continues to serve as a safe habour, so that even if the ultimate goal of the encounter does not materialise as fast as expected, both nurse and patient will be able to navigate "through the vulnerability emanating from the illness experience" (p.147).

Bergum (1992) observes that the essence of nursing and medicine is to assist individuals to heal themselves; but this means something different from person to person, thus, necessitating the rise of relational ethics and therapy. Emphasis on the notion of rights has clearly produced some benefits in clinical practice, including the rights of the patient to self-determination, informed consent, proper procedural education, and the like. However, closer examination reveals that rights-based ethic sooner than later "leads to a flattening and narrowing of our human life" because it inherently inhibits patient-nurse intersubjective relationship, which is the bedrock of relational method of clinical therapy (p.75). To be relationally ethical with a patient in practice, Bergum suggests, the 
professional would need to attend to certain specific questions, such as:

What kind of relationship is important in the clinical situation? What makes for right and good health care relation? What must the professional be and do? What are patients' responsibility in the relationship? (p.75)

Bergum frowns at the fact that clinical procedure, over the decades, has tended to relegate the person of the patient to the background, while 'strangers', such as lawyers, an ethics committee, rights advocates, and the like, make the decisions by rigorously debating over what counts as good for the patient. In the media, human casualties of war and epidemic are cast as mere statistics, rather than as real people who have actually lost their lives. The media also mislead society by emphasizing the crises that erupts between adopted children and their adoptive parents, unwittingly sidetracking these children's longing for "someone who looks like them ... [which gives them] a better sense of themselves through experiencing renewed relation with their birth mother and/or their genetic father" (Bergum, 1992, pp.76-77; original emphasis). These different experiences, Bergum argues, point to the need for a relational approach in current bioethical thinking orientated towards the particularity and uniqueness of clinical encounters and the individuals involved. Thus, Bergum submits that:

Ethical thinking in bioethics needs a new foundation with bricks formed by our understandings of the need for rights held together by our recognition of the need for care and relationship. Ethics built on 
this foundation moves past the rhetoric of rights (and its rational discourse) to a strong version of relationship (with its support of the moral relevance of emotion) toward a moral sense of love and respect in which one is caught by responsibility for the Other (p.79).

Bergum (2003, p.123) also discusses relational pedagogy and notes with concern that technology - though "the strength of modern medicine" - can easily become a dangerous trap disconnecting nurses from patients. Technology has the potentiality of rendering a practitioner insensitive to his or her patient's needs; replacing human action with mechanical operation; separating knowledge from experience; and deadening the nurse's emotions, making her to become less human. Power imbalance is another threat that can arise, due to the nurse's position of privilege, expertise and control, over the patient. All these are obstacles in the path of progress in relational ethics. But nurses are encouraged to develop observational skills, so that by applying the use of all their other senses, such obstacles may be surmounted and these misgivings laid to rest. Bergum (2003, p.126) puts it as follows:

[I]n the relational space where ... nurse and patient improvise, power loses its power. In fact, instead of power (and its worrisome implications - control, domination, coercion), we find words like listening, initiative, creativity, example, appropriate moment, leadership, letting be, and respect.

Shaw (2011) explores how relational ethics may inform ideas about the values-driven problems presented by people in therapy sessions. She proceeds to draw upon the traditions of moral philosophy and ethics in order to highlight ways of attending to 
values-driven issues that might be otherwise neglected. She finds that despite our inclination to view morality as judgmental and rule driven, moral conduct and decision-making can involve imaginative, creative and aesthetic possibilities. For over a period of ten years, Doane and Varcoe $(2005,2015)$ consistently apply the relational method of inquiry to family healthcare delivery and find it to be both satisfactory and rewarding, with minor adaptations and redesigning, as the occasion may require. Pollard (2015) and Upasen (2017) both identify the core elements of relational ethics to specifically include the following: (1) mutual respect, which refers to the capability for respecting others, and for self-respect, which elicits reciprocation; (2) engagement, referring to basic connection between nurse and patient, as facilitated by a sense of commitment, encouraging trust and openness; (3) embodiment, in relational ethics, is to the role emotion plays in ethical decisions and actions; and (4) interdependent environment, which is the requirement of relational ethics that we recognise that we exist interdependently in an environment. Attending to these elements can, according to Upasen (2017, p.6), "augment the skills psychiatric nurses currently use to establish therapeutic relationships with clients, as well as foster ethical practice." For Pollard, relational ethics marks a paradigm shift in clinical practice wherein people are seen as products of relationships, rather than as disjointed individuals. The ramification is that nursing is no longer merely about caring for patients, but about caring with them. Carnevale, Teachman and Bogossian (2017) also apply relational ethics in their study of children with complex health care needs and their parents. They found that the children's and their parents' interests are relationally intertwined and interdependent, and also 
that relational ethics can serve as framework for promoting clinical practices that are ethically attuned to the complexity of the needs of such children. Recently, Fritz and Holton (2019) have criticised contemporary practice for relying more on ordering loads of medical examinations and clinical investigations for patients, merely culminating in the dispensation of tons of drugs; they argue instead for openness, transparency and caring relationships that can engender trust and bring about healing, often at no extra financial cost to the client.

\section{Critique}

Gadow examines three layers of nursing ethics, leading her reader to expect that the rest of the paper would be focused on demonstrating exactly how the three layers may be effectively combined in clinical therapy. Naturally, this would endow the discussion with a high degree of neutrality and objectivity. Rather, one finds that Gadow's paper is turgid with disdain for rationalism, in the fashion that has become associated with Gilligan (1982); disdain she makes no pretenses about. After a brief explanation of the first ethical cornerstone she calls ethical immediacy, Gadow launches a fierce and long-running attack against ethical rationalism, following which she introduces her favoured relational narrative. She then goes on to romanticise this third way, embellishing her argument with its apparent advantages over the first two layers. She does not dwell on any shortcomings of the favoured third way, or on the objections that may be advanced against it. At some point, Gadow calls for the combination of the three layers, apparently realising that reason and professionalism cannot be separated in nursing practice; but her ambivalence is already apparent in the fact that she simultaneously crowns 
relational narrative - that favoured third way - with the lofty title of the postmodern turn in nursing ethics, as noted earlier.

Albeit, even more interesting is the fact that a thread linking Gadow's thought to those she criticises can be traced through to Kant, perhaps up to Descartes. Descartes proposes the suspension of judgment and certainty about knowledge, except for those ideas that are "clear and distinct" in the process of cogito. He holds that knowledge of, and certainty about, existence can only emanate from the thinking individual, who would then proceed to determine what is true (for themselves) from this already logically established basis (Descartes, 1997, p.176f.). These ideas are the threshold of Gadow's (1999, p.64) notion of "radical contingency," according to which meaning is determined and created by the agents involved in a given relational setting.

Gadow locates Kant, whose ethics of respect for persons as ends in themselves is at the very basis of Gadow's idea of engagement of the patient as co-creator of relational narrative in the clinic; for how is the nurse supposed to engage a patient without due respect for him as a human subject, rather than an object of clinical curiosity? Gadow's train of thought then moves on to the Humanists of the nineteenth century European philosophy, who emphasised human dignity and consciousness. It cuts through the existentialist philosophers, such as Sartre and Nietzsche, and connects Husserl, and then Merleau-Ponty, whose phenomenology may also be used to further illustrate the depth of influence which Gadow has garnered.

In his most celebrated work, Phenomenology of Perception (1945/2012), Merleau-Ponty encapsulates the cardinal elements of relational ethics highlighted above, namely embodiment, 42 
engagement, interdependent environment and mutual respect. One of his main contributions to existential phenomenology is his unique emphasis on the body as the point of reference of all perceptive experience; a facet which other philosophers apparently took for granted and rarely discussed with the same level of content and detail. In fact, Merleau-Ponty regards the body as the basic, starting point of all perceptual phenomena and experience. For him, the body is not just a biological or physical unit; rather, it is the body that structures our situation and experience within the world. It is by virtue of the body that perception precedes language, reason and thought. Though he does not use the precise term, the element of engagement is implicitly referred to in several places. For example, Merleau-Ponty states in one of many passages that:

The phenomenological world is ... inseparable from subjectivity and intersubjectivity, which establish their unity through the taking up of my past experiences into my present experiences, or of the other person's experience into my own (p. lxxxiv).

Elsewhere, he notes that "the body, by withdrawing from the objective world, will carry with it the intentional threads that unite it to its surroundings and that, in the end, will reveal to us the perceiving subject as well as the perceived world" (cited in Landes, 2012, p.xl). These excerpts make clear reference to thoroughgoing engagement of the professional nurse with the patient ("subject"); the excerpts convey the interdependency of the two, in terms of "intersubjectivity" and exchange of "experience". The "phenomenological world" in which this exchange takes place captures the immediacy of the experience and environment, as well as bodily presence of nurse and patient, while the idea of "present experience" depicts the here and now of clinical encounter, as 
understood by Gadow. Mutual respect is implied in the very idea of taking up the other person's experience into one's own, as well as the themes of freedom and temporality which Merleau-Ponty treats at some length later in the work. These are bits of evidence of how deeply Gadow is influenced by the different philosophical traditions, including rationalism, even though the stakes are too high for these influences to be admitted.

If Kohlberg's model of human ethical development is stereotyped, as Gilligan maintains, then so are care ethics and its near relative, relational ethics, particularly as articulated by Sally Gadow. Gilligan accuses Kohlberg's model of being maleoriented, and not reflecting women's true moral psychology. To strike the purported balance, she discards the rationalist blend of ethics presumably represented by Kohlberg, and proposes an ethic of care as the antidote that represents women's view, attitude and response to ethical matters (Malan and Cilliers, 2004). Above, we saw that Gadow's relational narrative shares some basic grounds with Gilligan's care ethics in its valuing of care respect. With this close proximity of both women's thoughts - rationalist thinking being, as they claim, the stock-in-trade of the male folk-and care ethics designed, as it is, with women in mind, how would Gadow's proposal apply to male nurses? Does Gadow suggest thereby that nursing is a decidedly female vocation, in which case her theory may equally be charged with the creation of stereotypes? This is, in fact, what most relational ethicists tacitly suggest when they depict rationalism as a male trait, in the bid to argue for the 'feminine' nature of relational ethics. They basically leave us with no other choice except that between rationalism and ethics of care, with men and women strategically positioned on the respective 
sides of this divide. If this is so, then the arguments advanced by Gadow do not apply to male nurses, in which case her critique of rationalist ethics would not amount to much.

What exactly does it mean, in health care, for a nurse to engage in close relational narrative with a patient? This is a central question that has received diverse answers from independent relational ethicists. Yet the feasibility of relational narrative - as a proposal-squarely rests on how coherently the question is addressed. What precisely is involved in this interaction? Is it open communication, trust and friendship, as Fritz and Holton (2019) have recently suggested? Or is it physical proximity, or tete-a-tete (Dowling, 2004; Wright and Brajtman, 2011; Alicea-Planas, 2016)? Is it spiritual union (Pesut, 2009)? But none of these things, in itself, guarantees sound practice any more than do the first two facets of Gadow's ethical cornerstone; and, regrettably, Gadow does not seem to make this notion explicit enough. To be rational in nurse-patient clinical experience does not, contrary to Gadow's pessimism in this regard, imply absolute unfriendliness and cold detachment of nurse from patient. Among other things, it involves balancing out a clinical situation in the light of reason, instead of plunging headlong into it, guided merely by the emotions, or the ethical codes of the practice, culture, or the prevailing religious beliefs of the circumstance in which the professional is working. Whatever else may be the case, it basically means the deployment of good sense in approaching a clinical encounter, rather than doing so simply as a matter of duty or routine, since each case has its own peculiar history and uniqueness, as Gadow herself points out. Hence, the question is: What is wrong about this? Rationalism, as a philosophical movement, certainly has excesses, just as do all other philosophical theories; but it has been an irresistible 
temptation, among scholars averse to rationalism, to jettison these excesses at the expense of the merits of rationalist philosophy, one of which is its identification of the critical role reason plays in human decision-making, in both ethical and non-ethical situations. Thus, if we insist on a dichotomy between reason and emotion, as proponents of care ethics and relational ethics apparently do, then the creation of alternative ethics (of care) for women - in which women are portrayed as typically emotionally inclined-tacitly suggests that women do not apply reason in ethical situations. Even more absurd is the fact that it portrays nursing as a profession devoid of reason, but full of mere human emotions and feelings.

Beyond the question of the precise nature of intimacy involved in a relational encounter, there is a further, separate question of the exact extent to which a nurse can be close to a patient, in order to achieve the co-creation of a relational narrative. What is the criterion, or yardstick, for determining when the closeness is adequate to elicit a narrative? Gadow emphasises the elements of body and physicality as necessary means of the relational narrative process. How is this supposed to be achieved with regard to patients with chronic contagious diseases, knowing that the body is the medium by which such diseases are transferred from one individual to another? Diseases do not, it would seem, have an independent existence per se, but typically survive and thrive in living tissues, in this case, the human body. Thus, even if we granted, for the sake of argument, that the relational approach can fit into the matrix of treating patients with non-contagious diseases, what about those suffering from contagious diseases? In this case, strict adherence to the principles of relational narrative apparently would put the nurse in a dilemma: either leave this crop 
of patients out of consideration altogether; or the nurse should expose herself to the disease in the process of trying to engage the patient closely, as demanded by Gadow. The first is not an option, because the code of ethics of the nursing profession certainly requires practitioners to seek the well-being of the patient. This leaves us with the second. What if every nurse simply walked straight into a contagious disease, such as the Ebola, or the current coronavirus (COVID-19) pandemic, and lost their life in the process, as did Nigeria's remarkable Dr. Stella Adadevoh (Otufodunrin, 2018), just because they needed to engage their patients more intimately? It seems, then, that at a certain level, reason and professionalism are indispensable in nursing practice; that while it is important to care for the patient by making them to feel relaxed, the ultimate goal or purpose of that entire exercise, which is healing and recovery, is not any less important, and should not be disregarded in the bigger picture of clinical encounter and practice.

Finally, no matter how intimate the nurse may get when dealing with a patient, a certain degree of professionalism would always be both required and called for. If there is no rationality, then there is no professionalism, which is the only factor that enables the nurse to be of any discernible degree of use to the patient. Professionalism requires a minimal degree of "standing back" so as to correctly assess a clinical situation, in order to find suitable solution. Were the professional to lose sense of direction (a scenario both conceivable and possible, given that a professional is not an automaton, but a human being with feelings and emotions), it is professionalism that pulls him or her back from the brink. It is only professionalism-in terms of training and application of reason and resort to extant code of conduct - that 
keeps the clinical procedure and process on track. In all these, the part played by reason is absolutely indispensable. Ultimately, Gadow has thrown rationalism out the front door, and, so, would end up smuggling it in through the back door again.

\section{Conclusion}

Sally Gadow is a child of her times. She has been deeply influenced by both foregoing scholarship and that of her age. These influences were those of Gilligan and Merleau-Ponty, and a horde of thinkers on the rationalist side, yet whose ideas she has tried so hard to jettison. But contrary to expectation, Gadow owes a lot to the perceived opponents she criticises unsparingly in her work, because her work is unavoidably dotted with traces of their ideas. Gadow (1999, p.59) apparently realises some of these pitfalls, and tries to address them in the later part of her paper, for example, by allowing that the three layers of nursing ethical cornerstone be dialectical in nature; that is, that they act as checks and balances on one another, which makes them "no longer mutually exclusive, but ... mutually enhancing." However, this later attempt is simply inconsistent with her exhausting critique of universal ethical rationalism, and her overarching thesis that relational narrative is the postmodern turn in nursing ethics. More critically, it clearly demonstrates that Gadow could never made a clean break from past ethical thinking; that her thought cannot be properly grounded without due consideration for rationalism. Thus, despite her distaste for rationalist philosophy, nuances of rationalism linger in her thought. 
Uche S. Odozor

Philosophy Unit, Department of Communication and General Studies, Federal University of Agriculture Abeokuta, Abeokuta. odozorus@funaab.edu.ng

Helen N. Obilor

Department of Nursing, Faculty of Clinical Sciences,

University of Ibadan.

ngoziobilor@yahoo.com

Olasupo O. Thompson

History Unit, Department of Communication and General Studies,

Federal University of Agriculture Abeokuta.

olakunleolasupo@yahoo.com

Ngozi S. Odozor

Department of Psychology,

University of Ibadan, Ibadan, Nigeria odo_val@yahoo.com 


\section{References}

Alicea-Planas, J. (2016). Listening to the narratives of our patients as part of holistic nursing care. Journal of holistic nursing. 34(2):162. DOI: 10.1177/0898010115591396.

Barcalow, E. (1994). Moral philosophy. California: Wordsworth.

Bergum, V. (2003). Relational pedagogy: Embodiment, improvisation, and interdependence. Nursing philosophy. 4:121-128. doi: 10.1046/j.1466-769x.2003.00128.x.

Bergum, V. (1992). Beyond rights: The ethical challenge. Phenomenology + pedagogy. 10: 75-84. DOI: https://doi.org/10.29173/pandp14904.

Carnevale, F. A., Teachman, G., \& Bogossian, A. (2017). A relational ethics framework for advancing practice with children with complex health care needs and their parents. Comprehensive child and adolescent nursing. 40(4):268284. https://doi.org/10.1080/24694193.2017.1373162.

Descartes, R. (1997). Meditations on first philosophy. In ChávezArvizo, E. (Ed.). Descartes: Key philosophical writings (pp.123-190). London: Wordsworth.

Dillon, R. (1992). Respect and care: Toward moral integration. Canadian journal of philosophy. 22:105-131. https://doi.org/10.1080/00455091.1992.10717273. 
Doane, H.G. \& Varcoe, C. (2015). How to nurse: Relational inquiry with individuals and families in changing health and health care contexts. Philadelphia, PA: Lippincott Williams and Wilkins.

Doane, H.G. \& Varcoe, C. (2005). Family nursing as relational inquiry. Philadelphia, PA: Lippincott Williams and Wilkins.

Dowling, M. (2004). Exploring the relationship between caring, love and intimacy in nursing. British journal of nursing. 13(21):1289. DOI: 10.12968/bjon.2004.13.21.17127.

Fritz, Z. and Holton, R. (2019). Too much medicine: Not enough trust? Journal of medical ethics. 45:31-35. doi:10.1136/medethics-2018-104866.

Gadow, S. (1999). Relational narrative: The postmodern turn in nursing ethics. Scholarly inquiry for nursing practice: An international journal. 13(1): 57-70. DOI:10.1891/08897182.13.1.57.

Gadow S. (1996). Ethical narratives in practice. Nursing science quarterly. 9(1): 8-9. https://doi.org/10.1177/089431849600900104.

Gilligan, C. (1990). Making connections: The relational worlds of adolescent girls at Emma Willard School. Cambridge, MA: Harvard University Press. 
Gilligan, C. (1982). In a different voice: Psychological theory and women's development. Cambridge, MA: Harvard University Press.

Hamlyn, D.W. (1967). Epistemology, History of. In Edwards, P. (Ed.). The encyclopedia of philosophy (pp.3-38). Vol.3. New York: Macmillan.

Hess, J.D. (2003). Gadow's relational narrative: An elaboration. Nursing philosophy. 4(2): 137-148. https://doi.org/10.1046/j.1466-769X.2003.00126.x.

Johnson, O.A. (1989). Ethics: Selections from classical and contemporary writers. 6th ed. London: Holt, Rinehart and Winston.

Kant, I. (1875/1953). Groundwork for the metaphysics of morals. Transl. H.J. Paton. London: Hacket.

Kohlberg, L. (1984). Essays on moral development: Vol.2. The philosophy of moral development. San Francisco CA: Harper \& Row.

Kohlberg, L. (1958). The development of modes of moral thinking and choice in the years 10 to 16 . Doctoral dissertation, University of Chicago. 
Landes, D.A. (2012). Translator's introduction. In MerleauPonty's Phenomenology of perception (pp. xxx-li). Transl. Donald A. Landes. New York: Routledge.

Macionis, J.J. and Plummer, K. (2005). Sociology: A global introduction. 3rd Ed. New York: Pearson Educational.

MacMurray, J. (1935). Reason and emotion. London: Faber.

Malan, Y. and Cilliers, P. (2004). Gilligan and complexity: Reinterpreting the 'Ethic of care'. Acta Academica. 36(3), $1-20$.

Merleau-Ponty, M. (1945/2012). Phenomenology of perception. Transl. Donald A. Landes. New York: Routledge.

Otufodunrin, L. (May 27, 2018). Ebola: Remembering Stella Adadevoh. The Nation. Retrieved October 19, 2018, from: http://thenationonlineng.net/ebola-remembering-stellaadadevoh/

Owens, M. (1969). The notion of human rights: A reconstruction. American philosophical quarterly. 6:241-248.

Pesut, B. (2009). Incorporating patient's spirituality into care using Gadow's ethical framework. Nursing ethics. 16(4):418. doi: 10.1177/0969733009104606.

Pollard, C.L. (2015). What is the right thing to do: Use of a relational ethic framework to guide clinical decision- 
making. International journal of caring sciences. 8(2):362368.

Rachels, J. (2003). The elements of moral philosophy. 4th Ed. New York: McGraw-Hill.

Rawls, J. (1971). A theory of justice. Cambridge: Harvard University Press.

Shaw, E. (2011). Relational ethics and moral imagination in contemporary systemic practice. The Australian and New Zealand journal of family therapy. 32(1):1-14. https://doi.org/10.1375/anft.32.1.1.

Stratton-Lake, P. (2006). Moral motivation in Kant. In Bird, G. (Ed.). A Companion to Kant (pp. 308-334). Oxford: Blackwell.

Upasen, R. (2017). Relational ethics and nurses-client relationship in nursing practice: Literature review. Mental health \& human resilience international journal. 1(1):1-8. doi: 10.23880/mhrij-16000102.

Wright, D. and Brajtman, S. (2011). Relational and embodied knowing: Nursing ethics within the interprofessional team. Nursing ethics. 18(1):20-30. doi: 10.1177/0969733010386165. 